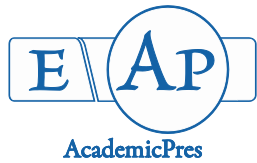

\title{
Litsea glutinosa (Lauraceae): Evaluation of its Foliar Phytochemical Constituents for Antimicrobial Activity
}

\author{
Aniel Kumar OWK ${ }^{1}$, Mutyala Naidu LAGUDU ${ }^{2 *}$ \\ ${ }^{1}$ Andhra University, Department of Botany, Visakhapatnam-530003, Andhra Pradesh, India \\ ${ }^{2}$ Adikavi Nannaya University, Department of Botany, Rajamahendravaram-533296, Andhra Pradesh, \\ India; lagudu3@gmail.com (*corresponding author)
}

\begin{abstract}
The phytochemical investigation of the leaves of Litsea glutinosa revealed the presence of secondary metabolites like alkaloids, anthraquinones, cardiac glycosides, flavonoids, glycosides, phenols, saponins, steroids, tannins, terpenoids, volatile compounds, amino acids and carbohiydrates. The antimicrobial activity and minimum inhibition concentration values were determined for these phytochemical constituents as crude extracts using the agar well diffusion and two-fold serial dilution methods. The results indicated that Bacillus subtilis was the most susceptible bacterium with high inhibition zones for the methanol and chloroform extracts of $31 \mathrm{~mm}$ and $26 \mathrm{~mm}$, respectively. The MIC values indicated that extracts possess good antimicrobial activity with significant MIC value against Enterococcus faecalis, Pseudomonas aeruginosa and Staphylococcus pneumoniae at $31.2 \mu \mathrm{g} / \mathrm{ml}$ concentrations. The extracts showed marked antimicrobial activity against both bacteria and fungi. Among the bacterial strains, gram-positive bacteria were more susceptible than the gram-negative. All the 13 microorganisms tested showed dose dependent susceptibility towards the phytochemicals present in the foliar extracts. The study suggests that Litsea glutinosa leaves possess potent antimicrobial activity and can be a good source for the development of new antibiotics.
\end{abstract}

Keywords: extract; Litsea glutinosa; microorganism; pathogen; phytochemical

\section{Introduction}

In India, from ancient times, different parts of medicinal plants have been used to treat the infectious diseases which are the cause of premature deaths to an extent of 50,000 people every day globally (Anonymous, 2000). India is rich in medicinal plant diversity because of different agroclimatic, ecological and edaphic conditions. Medicinal plants are the richest source of natural products for traditional system of medicine, pharmaceutical intermediates and chemical entities for synthetic drugs. Thus, there is a constant need to develop new antimicrobial drugs for the treatment of infectious diseases from the medicinal plants (Ncube et al., 2008).

Litsea glutinosa (Lour.) C.B. Robinson (Lauraceae) is an evergreen or deciduous, that reaches a height of 3-15 meters. This species is native to India, South China to Malaysia, Australia and the western Pacific Islands. It is a medicinal plant known as Indian laural, soft/brown bollygum or beech/bolly beech, bollywood and sycamore. In Telugu, it is called 'narra alagi' or 'narra mamidi'. It is a threatened species due to over exploitation for its bark and considered as endangered species in Philippines (Rabena, 2010). Traditionally, it is considered as promoter of longevity, semen generation and emollient. The sap of fresh bark or its decoction is prescribed as a remedy for diarrhoea, dysentery and rheumatism. The mucilaginous leaves are considered antispasmodic and emollient. In addition, a paste prepared by grinding bark with water is used as a plaster in cases of sprain, bruises, wounds, inflammation, back pain, rheumatic and gouty joints, bone fractures, etc. It has analgesic, antiseptic and emollient effects (Devi and Meera, 2010). Although the most of the antimicrobial activities had been carried out on the bark extract (Mandal et al., 2000; Lohitha et al., 2010; Poornima, 2011; Haque et al., 2014) there are a few studies on the antimicrobial activity on methanol extracts of leaves(Meera and Devi, 2009; Gulzar et al., 2015). However, there are no reports on the antimicrobial activity of L. glutinosa leaves, and their effects on pathogenic fungi and bacteria. Thus, the present study evaluated the antimicrobial activity of hexane, chloroform, methanol and aqueous extracts of $L$. glutinos a leaves. 


\section{Materials and Methods}

\section{Plant material}

The leaves of Litsea glutiona were collected from Andhra University campus of a planted tree from Visakhapatnam, Andhra Pradesh, India. Its taxonomic identity was confirmed by Prof. M. Venkaiah, Department of Botany, Andhra University, Visakhapatnam, India. The leaves collected were shade-dried. Then, they were powdered in the mixture grinder and stored in airtight bottles.

\section{Extraction of plant material}

The shade dried leaf powder ( $10 \mathrm{~g}$ of each) was extracted with hexane, chloroform, followed by methanol by using sequential extraction method (Aniel Kumar et al., 2010). Thereafter, it was filtered by rotary evaporator at $40{ }^{\circ} \mathrm{C}$ to obtain the crude dried extract. Simultaneously, the aqueous extract of the leaves was prepared by adding boiled water to the powdered in a beaker on water bath, with occasional stirring for 4 hours. The aqueous extract was then filtered and centrifuged at 5,000 rpm for $15 \mathrm{~min}$. The supernatant was collected and evaporated to dryness to give the crude dried extract. The extracts were dissolved in DMSO to get the known concentrations of $25 \mathrm{mg} / \mathrm{ml}, 50 \mathrm{mg} / \mathrm{ml}$ and 100 $\mathrm{mg} / \mathrm{ml}$.

\section{Microbialstrains}

The test bacterial and fungal strains used in the study were obtained from Microbial type culture and collection (MTCC), Chandigarh, India. They are Bacillus subtilis MTCC B2274, Enterococcus faecalis MTCC B3159, Escherichia coli MTCC B1560, Klebsiella pneumoniae MTCC B4030, Micrococcus luteus MTCC B1538, Pseudomonas aeruginosa MTCC B2297, Proteus vulgaris MTCC B7299, Staphylococcus aureus MTCC B3160, Streptococcus pneumoniae MTCC B2672, Aspergillus niger MTCC F4325, Candida albicans MTCC F7315 and Saccharomyces cerevisiae MTCC F2567. The bacterial strains were grown in the nutrient broth and maintained on nutrient agar slants at $4^{\circ} \mathrm{C}$ whereas the fungal strains were grown in Sabouraud broth and maintained on Sabouraud agar slants $C$. albicans and $S$. cerevisiae) and potato dextrose agar slants $(A$. niger $)$ at $4^{\circ} \mathrm{C}$.

\section{Antimicrobial screening}

The antimicrobial activity of hexane, chloroform, methanol and aqueous extracts of leaves of L. glutinosa was determined by agar well diffusion (Aniel Kumar et al., 2014) and agar disc diffusion methods for standard antibiotics tetracycline and fluconazole separately for bacteria and fungi. The lyophilized culture was sub cultured and concentration of working stock culture was assessed as $10^{-6} \mathrm{CFU} / \mathrm{ml}$. For susceptibility test, $100 \mu \mathrm{l}$ of inoculum was mixed with $6 \mathrm{ml}$ of sterilized nutrient agar and poured immediately into the sterile petridishes. The petridishes were left to solidify for 10 minutes. A sterilized $6 \mathrm{~mm}$ metal borer was used to make wells in the centre of the divided areas. About $50 \mu \mathrm{l}$ of each extract was then pipette into the wells. The petridishes were incubated at $28^{\circ} \mathrm{C}$ for 24 hours.
The experiment was done three times to minimize the error. After incubation period the antimicrobial activity was evaluated by measuring the inhibition zones by using an antibiotic zone reader scale(HiAntibiotic Zonescale-c).

Sabouraud agar was used to culture the fungi. The inoculated petridishes were incubated at $25^{\circ} \mathrm{C}$ for two days for the $C$. albicans, $S$. cerevisiae and three days for $A$. niger. About $500 \mu \mathrm{g}$ of fluconazole was dissolved in $1 \mathrm{ml}$ of sterile deionized water. About $10 \mu \mathrm{l}$ of $0.5 \mathrm{mg} / \mathrm{ml}$ of fluconazole (equivalent to $5 \mu \mathrm{g}$ dose) pipette into the wells for comparison with fungal inhibition zones. The bacterial inhibition zones were was compared with tetracycline disc $(5 \mu \mathrm{g} / \mathrm{disc})$ of multidrug disc (Axiom Laboratories Ltd. India). About $50 \mu \mathrm{l}$ of DMSO was pipette into each well for bacteria and fungi as a negative control.

The extracts that exhibited inhibition zones were subjected to minimum inhibition concentration (MIC) assay by using two-fold serial dilution (Aniel Kumar et al., 2015). A quantity of $0.6 \mathrm{~g}$ of each extract was dissolved in $300 \mathrm{ml}$ sterile nutrient broth which yields initial concentration of $2,000 \mu \mathrm{g} / \mathrm{ml}$. Subsequently, two-fold serial dilution was made from the stock to obtain 1,000, 500, 250, 125, 62.5, $31.2 \mu \mathrm{g} / \mathrm{ml}$ concentrations. One $\mathrm{ml}$ of standardized inoculums of each test organism was introduced into each extract nutrient broth mixture and then incubated at $370 \mathrm{C}$. The lowest concentration inhibiting growth was regarded as the MIC of the extracts.

\section{Statistical analysis}

Each experimental data from triplicates of standard error was subjected to one way ANOVA using Minitab version 15 . The significant level of $\mathrm{p}<0.001$ was used.

\section{Results and Discussion}

The phytochemical analysis of various extracts of the leaf revealed the presenceof secondary metabolites like alkaloids, anthraquinones, falvonoids, phenols, saponins, steroids, tannins, terpenoids, volatile compounds, cardiac glycosides, glycosides, amino acids and carbohydrates (Table 1). There are numerous secondary metabolites such as Megastigmane diglycoside, roseoside, 3, 5'-dimethoxy-9, 9'-dihydroxy-4, 7'epoxylignan 4'-b-D-glucopyranoside, dihydro dehydrodiconifenyl alcohol 9'-O-b-D-xylopyranoside; and Pinoresinol 3-O-b-D-glucopyranoside reported from $L$. glutinosa leaves and twigs (Wang et al., 2011). A new 2'Oxygenated Flavone Glycoside, named Glutin was isolated from the leaf extract of $L$. glutinosa (Wang et al., 2010). Tannin, $\beta$-sitosterol and actinodaphnine are reported to be the common constituents of the species. Major clusters of antimicrobial compounds including alkaloids (Feng et al., 2009), butanoides (Chang et al., 2008), flavonoids (Wang and Liu, 2010), lignans (Pan et al., 2010), sesquiterpenes (Agarwal et al., 2011), and essential oils (Chowdhary et al., 2008) have been discovered in Litsea spp. These compounds have shown significant biological activities including anti-inflammatory (Devi and Meera, 2010), antitumor (Cheng et al., 2010), anticancer (Hosseinzadeh et al., 2013), antioxidant (Jia et al., 2013), antidepressant (Guzman and Navarrete, 2009) and antiphyperalgesic (Silva et al., 2012) properties. 
Table 1. Phytochemical constituents of Litsea glutionosa leaves

\begin{tabular}{|c|c|c|c|c|}
\hline Phytochemical constituents & Hexane extract & Chloroform extract & Methanol extract & Aqueous extract \\
\hline Alkaloids & + & + & + & + \\
\hline Amino acids & + & + & + & + \\
\hline Anthraquinone & - & - & - & - \\
\hline Carbohydrates & + & + & + & + \\
\hline Cardiac glycosides & - & - & + & - \\
\hline Flavonoids & - & + & + & + \\
\hline Glycosides & + & + & + & + \\
\hline Phenols & - & + & + & - \\
\hline Saponins & + & + & + & + \\
\hline Steroids & - & + & + & - \\
\hline Tanins & - & - & + & + \\
\hline Terpenoids & + & + & + & + \\
\hline Volatile compounds & + & + & + & + \\
\hline
\end{tabular}

In the present study, the extracts of $L$. glutinosa leaves exhibited the antimicrobial activity against all tested bacteria and fungi except that $A$. niger was resistant to the hexane and chloroform extracts (Table 2). B subtilis was the most susceptible bacteria with high inhibition zones for the methanol and chloroform extracts of $31 \mathrm{~mm}$ and $26 \mathrm{~mm}$, respectively. Aqueous extract showed the high inhibition zone against $S$. pneumoniae and $P$. aeruginosa while hexane extract against $M$. luteus and $K$. pneumoniae. The fungal strain $S$. cerevisiae was more susceptible to all extracts than other fungal strains $A$. niger and $C$. albicans. The most susceptible gram positive bacterium is $B$. subtilis for all extracts while the gram-negative bacterium is $P$. aeruginosa. When the concentration of these extracts was increased, the inhibition zones also increased and it indicated dose dependent susceptibility.

The results of antibacterial and antifungal of the different extracts of $L$. glutinosa leaves were compared with the standard antibiotics. The extracts showed inhibition zones were similar or more than the antibiotics against in more than $50 \%$ of the investigated microbial strains. It is a promising result and suggests that the plant extracts contain certain phytochemical constituents with antimicrobial properties that can be used to develop new drugs for therapy of infectious diseases caused by microorganisms.

The MIC values indicate that the leaf extracts of $L$. glutinosa possess antibacterial activity against $B$. subtilis, $E$. faecalis, $S$. pneumoniae and $P$. aeruginosa at $31.2 \mu \mathrm{g} / \mathrm{ml}$ concentrations (Table 3). These bacteria also shown strong MIC values for aqueous and chloroform extracts at 62.5 $\mu \mathrm{g} / \mathrm{ml}$ concentration. These results agree with previous studies, ethanol extracts of bark shown antibacterial activity against $S$. aureus, $B$. cereus, $P$. aeruginos a and $E$. coli (Lohitha et al., 2010), while the same extract active against $P$. aeruginosa, $E$. coli, $S$. aureus but less effective against fungal strains A. fumigates and C. albicans (Poornima, 2011). Ethanolic and water extracts of bark and leaves have antibacterial activity against $E$. coli, Enterobacter intermedium, Salmonella sp., $S$. aureus and $S$. epidermis (Haque et al., 2014), while leaves shown antimicrobial activity against gram-negative $S$. paratyphi (Gulzar et al., 2015) and methanol extract of bark shown antibacterial activity against 16 microorganisms tested (Mandal et al., 2000).

Table 2 . The antimicrobial activity of $L$. glutinosa leaf extracts against the standard drugs

\begin{tabular}{|c|c|c|c|c|c|c|c|c|c|c|c|c|c|c|}
\hline & \multicolumn{14}{|c|}{ Inhibition zones $(\mathrm{mm})^{2}$} \\
\hline & \multicolumn{3}{|c|}{ Hexane extract } & \multicolumn{3}{|c|}{ Chloroform extract } & \multicolumn{3}{|c|}{ Methanol extract } & \multicolumn{3}{|c|}{ Aqueous extract } & \multirow{2}{*}{ S } & \multirow{2}{*}{ D } \\
\hline & 25 & 50 & 100 & 25 & 50 & 100 & 25 & 50 & 100 & 25 & 50 & 100 & & \\
\hline B. subtilis & $16 \pm 0.19$ & $18 \pm 0.50$ & $20 \pm 0.45$ & $21 \pm 0.52$ & $23 \pm 0.44$ & $26 \pm 0.40$ & $28 \pm 0.19$ & $29 \pm 0.19$ & $31 \pm 0.45$ & $18 \pm 0.12$ & $20 \pm 0.48$ & $21 \pm 0.50$ & $18^{\mathrm{T}}$ & - \\
\hline E. faecalis & $16 \pm 0.28$ & $18 \pm 0.44$ & $19 \pm 0.22$ & $18 \pm 0.44$ & $21 \pm 0.22$ & $23 \pm 0.22$ & $24 \pm 0.20$ & $26 \pm 0.44$ & $28 \pm 0.20$ & $17 \pm 0.40$ & $18 \pm 0.20$ & $19 \pm 0.28$ & $21^{\mathrm{T}}$ & - \\
\hline M. luteus & $18 \pm 0.44$ & $20 \pm 0.45$ & $21 \pm 0.44$ & $16 \pm 0.28$ & $18 \pm 0.45$ & $20 \pm 0.51$ & $19 \pm 0.40$ & $21 \pm 0.40$ & $23 \pm 0.44$ & $16 \pm 0.28$ & $18 \pm 0.45$ & $20 \pm 0.45$ & $24^{\mathrm{T}}$ & - \\
\hline S. aureus & $16 \pm 0.44$ & $18 \pm 0.22$ & $20 \pm 0.44$ & $17 \pm 0.10$ & $19 \pm 0.19$ & $21 \pm 0.29$ & $16 \pm 0.34$ & $18 \pm 0.22$ & $20 \pm 0.04$ & $11 \pm 0.20$ & $13 \pm 0.19$ & $15 \pm 0.54$ & $24^{\mathrm{T}}$ & - \\
\hline S. pneumoniae & $12 \pm 0.22$ & $15 \pm 0.52$ & $17 \pm 0.22$ & $21 \pm 0.25$ & $23 \pm 0.40$ & $25 \pm 0.94$ & $25 \pm 0.22$ & $27 \pm 0.52$ & $29 \pm 0.20$ & $22 \pm 0.21$ & $24 \pm 0.24$ & $25 \pm 0.29$ & $22^{\mathrm{T}}$ & - \\
\hline E. coli & $10 \pm 0.28$ & $12 \pm 0.22$ & $14 \pm 0.52$ & $12 \pm 0.44$ & $14 \pm 0.50$ & $16 \pm 0.46$ & $15 \pm 0.88$ & $18 \pm 0.22$ & $21 \pm 0.52$ & $17 \pm 0.44$ & $19 \pm 0.50$ & $21 \pm 0.24$ & $22^{\mathrm{T}}$ & - \\
\hline K. pneumoniae & $17 \pm .19$ & $19 \pm 0.52$ & $21 \pm 0.50$ & $20 \pm 0.50$ & $22 \pm 0.22$ & $24 \pm 0.12$ & $23 \pm 0.19$ & $25 \pm 0.52$ & $27 \pm 0.55$ & $16 \pm 0.50$ & $18 \pm 0.02$ & $19 \pm 0.22$ & $24^{\mathrm{T}}$ & - \\
\hline P. aeruginosa & $15 \pm 0.44$ & $18 \pm 0.45$ & $20 \pm 0.44$ & $20 \pm 0.45$ & $22 \pm 0.52$ & $25 \pm 0.62$ & $25 \pm 0.44$ & $27 \pm 0.45$ & $29 \pm 0.04$ & $21 \pm 0.05$ & $23 \pm 0.52$ & $25 \pm 0.05$ & $25^{\mathrm{T}}$ & - \\
\hline P. vulgaris & $10 \pm 0.50$ & $11 \pm 0.52$ & $14 \pm 0.22$ & $15 \pm 0.22$ & $17 \pm 0.72$ & $19 \pm 0.20$ & $19 \pm 0.20$ & $21 \pm 0.22$ & $23 \pm 0.28$ & $17 \pm 0.29$ & $19 \pm 0.22$ & $21 \pm 0.08$ & $22^{\mathrm{T}}$ & - \\
\hline A. niger & - & - & - & - & - & - & $12 \pm 0.52$ & $14 \pm 0.50$ & $16 \pm 0.16$ & - & $10 \pm 0.20$ & $13 \pm 0.10$ & $18^{\mathrm{F}}$ & - \\
\hline C. albicans & $12 \pm 0.44$ & $13 \pm 0.45$ & $15 \pm 0.44$ & $12 \pm 0.52$ & $14 \pm 0.50$ & $16 \pm 0.50$ & $16 \pm 0.44$ & $18 \pm 0.65$ & $21 \pm 0.44$ & $16 \pm 0.30$ & $18 \pm 0.05$ & $19 \pm 0.29$ & $23^{\mathrm{F}}$ & - \\
\hline S. cerevisiae & $16 \pm 0.19$ & $18 \pm 0.45$ & $20 \pm 0.22$ & $18 \pm 0.19$ & $20 \pm 0.22$ & $23 \pm 0.25$ & $22 \pm 0.11$ & $24 \pm 0.45$ & $26 \pm 0.21$ & $14 \pm 0.19$ & $16 \pm 0.02$ & $18 \pm 0.50$ & $20^{\mathrm{F}}$ & - \\
\hline
\end{tabular}

a: Each value is the mean of three replicates, with standard deviation

$P<0.001$ extremely significant when compared to the standard S: Standard (T-Tetracycline; F- luconazole)

D: DMSO-: No activity 
Table 3. MIC values of Litsea glutinosa leaf extracts against the tested microorganisms

\begin{tabular}{lcccc}
\hline Organism & $\begin{array}{c}\text { Hexane } \\
\text { extract }\end{array}$ & $\begin{array}{c}\mathrm{ChCl}_{3} \\
\text { extract }\end{array}$ & $\begin{array}{c}\text { Methanol } \\
\text { extract }\end{array}$ & $\begin{array}{c}\text { Aqueous } \\
\text { extract }\end{array}$ \\
\hline E. faecalis & 500 & 125 & 31.2 & 500 \\
M. luteus & 250 & 250 & 125 & 250 \\
S. aureus & 500 & 250 & 250 & 1,000 \\
S. pneumoniae & 1,000 & 125 & 31.2 & 62.5 \\
E. coli & $>1,000$ & 500 & 250 & 250 \\
K. pneumoniae & 250 & 125 & 62.5 & 500 \\
P. aeruginosa & 500 & 500 & 31.2 & 62.5 \\
P. vulgaris & $>1,000$ & 1,000 & 125 & 125 \\
C. albicans & 1,000 & 250 & 250 & 1,000 \\
S. cerevisiae & 250 & 62.5 & 62.5 & 500 \\
\hline
\end{tabular}

The antimicrobial activity of the extracts on bacteria was more pronounced than on fungi. It could be due to the fungal cell wall which has a complex structure and extensive cross-linking between chitin, glucans and other polymers. It also was observed that gram-positive bacteria were more susceptible than the gram-negative as has been found by Meera and Devi (2009), who studied the methanol extract of L. glutinosa leaves and had the similar result. This difference in the activity may be attributed to the fact that the cell wall in gram-positive bacteria have of a single layer whereas the gram-negative bear multilayered structure along with more lipids. The present study also receives support from Ali et al. (2004).

The antimicrobial activity may be due to the presence of some metabolites like alkaloid, saponins and terpenoids which have been implicated in various biological activities (Thomas et al., 2013) and presently found in all the extracts. The present study suggests that $L$. glutinosa has great potential as a source of useful bioactive compounds which cure infectious diseases caused by pathogenic bacteria and fungi.

\section{Conclusions}

The L. glutinosa leaf extracts showed marked antimicrobial activity against both bacteria and fungi, while in the bacterial strains, gram-positive bacteria were more susceptible than the gram-negative. The extracts showed marked antimicrobial activity against both bacteria and fungi. The antimicrobial activity is dose dependent susceptibility towards the phytochemicals present in the solvent foliar extracts. Therefore, the study shows that $L$. glutinosa leaf extracts have a broad spectrum of antimicrobial activity and could be useful in antiseptic/disinfectant formulations and chemotherapy.

\section{References}

Agrawal N, Choudhary AS, Sharma MC, Dobhal MP (2011). Chemical constituents of plants from the genus Litsea. Chemistry \& Biodiversity 8:223-243.

Ali MA, Sayeed MA, Bhuiyan MSA, Sohel FI, Yeasmin MS (2004). Antimicrobial screening of Cassia fistula and Mesua ferrea. Journal of Medical Sciences 4:2429.
Aniel Kumar O, Krishna Rao M, Mutyala Naidu L (2014). Evaluation of antimicrobial activity of chemical constituents of $A$ chyranthes aspera $\mathrm{L}$. roots against human pathogens. Indian Journal of Natural Products and Resources 5(3):278-281.

Aniel Kumar O, Krishna Rao M, Mutyala Naidu L (2015). Evaluation of antimicrobial activity of root extracts of Abutilon indicum. Notulae Scientia Biologicae 7(2):160-163.

Aniel Kumar O, Mutyala Naidu L, Raja Rao KG (2010). Antibacterial evaluation of snake weed (Euphorbia hirta L.). Journal of Phytology 2(3):08-12.

Anonymous (2000). Centers for Disease Control and Prevention, Preventing emerging infectious diseases, astrategy for the $21^{\star}$ century.

Chang SY, Cheng MJ, Kuo YH, Lee SJ, Chen IS (2008). Secondary metabolites from the stem bark of Listea akoensis and their cytotoxic activity. Helvetica Chimica Acta91(6):1156-1165.

Cheng MJ, Wang TA, LeeSJ, Chen IS (2010). A new butanolide and a new secobutanolide from Litsea lii var. nunkao-tahangensis. Natural Product Research 24(7):647-656.

Chowdhury JU, Bhuiyan NI, Nandi NC (2008). Aromatic plants of Bangladesh: Essential oils of leaves and fruits of Lissea glutinosa (Lour.) C.B. Robinson. Bangladesh Journal of Botany 37(1):81-83.

Devi P, Meera R (2010). Study of antioxidant, anti-inflammatory and wound healing activity of extracts of Litsea glutinosa. Journal of Pharmaceutical Science and Research 2(2):155-163.

Feng T, Zhang RT, Tan QG, Zhang XY, LiuYP, Cai XH (2009). Two new isoquinoline alkaloids from Lissea cubeba. Zeitschrift fur Naturforschung B 64:871-874.

Gulzar H, Chowdhury M, Alam MN, Alam S, Shakil M, Khan S, Rahman M, Mazumdar M (2015). Phytochemical screening, antimicrobial and anticancerous activities of two different plant extracts. Journal of Medicinal Plants Studies 3(6):76-81.

Guzman GSI, Navarrete A (2009). Pharmacological exploration of the sedative mechanism of hesperidin indentified as the active principle of Citrussinensis flowers. Planta Medica 75:295-301.

Haque T, Uddin MZ, Saha M, Mazid A, Hassan A (2014). Propagation, antibacterial activity and phytochemical profiles of Lissea glutinosa (Lour.) C.B. Robinson. Dhaka University Journal Biological Sciences 23(2):165-171. 
Hosseinzadeh M, Mohamad J, Khalilzadeh MA, Zardoost MR, Haak J, Rajabi M (2013). Isolation and characterization of bioactive compounds from the bark of Litsea costalis. Journal of Photochemistry Photobiology B 128:85-91.

Jia XJ, Dong L, Yang Y, Yuan S, Zhang ZW, Yuan M (2013). Preliminary structural characterization and antioxidant activities of polysaccharides extracted stem Hawk tea (Litsea coreana var. lanuginose). Carbohydr Polymers 95:195-199.

Lohitha P, Shivsagar K, Charan V, Priya UP, Sagar SV, Ramanjaneyulu K, Verma V (2010). Phytochemical screening and evaluation of in vitro antibacterial activity of Litsea glutinosa (L) bark ethanol extract. Pharmacologyonline 1:618-623.

Mandal SC, Kumar CK, Majumder A, Majumder R, Maity BC (2000). Antibacterial activity of Litsea glutinosa bark. Fitoterapia 71(4):439-441.

Meera R, Devi P (2009). Antimicrobial activity of methanolic extract of Merrimea gagentica and Litsea glutinosa Leaves. Asian Journal of Chemistry21(7):5655-5660.

Ncube NS, Afolayan AJ, Okoh AL (2008). Assessment techniques of antimicrobial properties of natural compounds of plant origin: current methods and future trends. African Journal of Biotechnology 7(12):1797-1806.

Pan JY, Zhang S, Jun W, Li QX, Xiao ZH (2010). Litseaglutinan A and lignans from Litsea glutinosa. Helvetica Chimica Acta 93(5):951-957.
Poornima VH (2011). Evaluation of antimicrobial activity of Litsea glutinosa. International Journal of Pharmaceutical Applications 2(1):105-114.

Rabena AR (2010). Propagation techniques of endangered sablot (Litsea glutinosa) Lour. C.B. Robinson. JPAIR Multidisciplinary Journal 5:5683.

Silva KA, Klein Junior LC, Cruz SM, Caceres A, Quintao N, Monache FD (2012). Anti-inflammatory and anti-hyperalgesic evaluation of the condiment laurel (Litsea guatemalensis Mez.) and its chemical composition, Food Chemistry 132(4):1980-1986.

Thomas RP, Antony AM, Mamen AA (2013). Comparative phytochemical analysis of Diospyros chloroxylon leaves in various extracts. International Journal of Scientific and Research Publications 3(9):14.

Wang H, Liu Y (2010). Chemical composition and antibacterial activity of essential oils from different parts of Litsea cubeba. Chem Biodivers 7:229-235.

Wang YS, Huang R, Lu H, Li F, Yang JH (2010). A new 2'-oxygenated flavones glycoside from Litsea glutinosa (Lour.) C.B. Rob. Biosciences Biotechnology Biochemistry 74(3):652-654.

Wang YS, Zhen L, Yan L, Rong H, Hong BZ, Jing Y (2011). A new Megastigmane Diglycoside from Litsea glutinosa (Lour.) C. B. Rob. Journal of Brazilian Chemical Society 22(11):22342238 